\title{
COVID-19 pandemic and the healthcare workers- The call of duty
}

\author{
Shaib MUHAMMAD 1 * (D), Geeta KUMARI 1 (D), Narendar KUMAR 1 (D), Rafia TABASSUM 2 (D), \\ Muhammad Saleh KHASKHELI 2 (D), Jabbar ABBAS 3 (D), Razia SULTANA 3 (D), \\ Sadaf Hayat LAGHARI 4 (D)
}

1 Faculty of Pharmacy, University of Sindh, Jamshoro, Pakistan.

2 Department of Anaesthesiology, SICU and Pain Centre, Peoples University of Medical and Health Sciences for Women, Nawabshah, Shaheed Benazirabad, Pakistan.

3 Institute of Pharmaceutical Sciences, Peoples University of Medical and Health Sciences for Women, Nawabshah, Shaheed Benazirabad, Pakistan.

4 College of Pharmacy, Liaquat University of Medical and Health Sciences, Jamshoro, Pakistan.

* Corresponding Author. E-mail: shoaib@usindh.edu.pk (S.M.); Tel. +92-333-270 4104.

Received: 24 January 2021/ Revised: 07 July 2021/ Accepted: 14 July 2021

\begin{abstract}
COVID-19 is the current topic of discussion globally as people are getting affected by it on a huge scale. This study is focused to determine the concerns and perceptions of healthcare workers (HCWs) due to the COVID-19 pandemic and its effect on their mental health, routine work, family and social life. Study was conducted at various health care facilities of Sindh, Pakistan, from October to December 2020 (three months). An online survey questionnaire consisting of fourteen closed-ended questions was designed in Google Forms and circulcalted among the HCWs through email and social media. The data collected was analyzed using SPSS 24 and descriptive statistical tools were used to measure the frequencies and the Chi-square test was applied among correlated variables. Among 412 respondents, majority of the participants were male (54.6\%) and young with 18-28 years of age (47.3\%). Two-third of HCWs were highly concerned about their family's health versus own health $(67.7 \%$ vs $44.7 \%$ respectively) and 157 (38.1\%) were emotionally distressed. It was also found that HCWs with assigned duties in the isolation wards were more emotionally distressed (56.2\% high to very high) compared to those not working in isolation units (45.3\% high to very high). More than half of HCWs (51.9\%) reported that their family life was also disturbed. Our findings indicate that COVID-19 pandemic has a significant psychological impact on frontline soldiers (HCWs) particularly they were worried about family's health. The HCWs who were assigned duties in isolation units were more emotionally distressed than those who were not assigned duties in isolation wards.
\end{abstract}

KEYWORDS: COVID-19; health worry; healthcare workers; emotional distress; pandemic.

\section{INTRODUCTION}

Healthcare workers (HCWs) are the frontline soldiers and play very crucial role in containing the spread of paendemics. By doing so, HCWs not only place their own health at risk, but also the health of their family members. During the Severe Acute Respiratory Syndrome Coronavirus (SARS-CoV) outbreak in 2003 in Toronto (Canada), out of 71 patients admitted to Sunnybrook and Women's College Health Sciences Center, due to SARS-CoV infection symptoms, 23 were HCWs. Things eventually got so bad that many HCWs were quarantined and three of the hospitals were closed at various times becuase of HCWs were getting quarantined [1]. A similar situation occurred in the Republic of South Korea during the Middle East Respiratory Syndrome Coronavirus (MERS-CoV) outbreak in 2015 where out of 186 MERS-CoV diagnosed patients, 26 were HCWs [2]. As of October 2020, tens of millions of people are infected with the Coronavirus (COVID-19), and more than a million death have been reported, surpassing the total number of deaths caused by the Severe Acute Respiratory Syndrome (SARS) and Middle East Respiratory Syndrome (MERS) [3-5]. Among the infected are hundreds of HCWs. More than fifty deaths of HCWs have been reported in Italy and this number continues to grow throughout the world [6].

During the pandemics, HCWs are working in stressful environments so emotional and behavioral impact are obviously caused by stress conditions in which they work due to unpredictability of the situation.

How to cite this article: Muhammad S, Kumari G, Kumar N, Tabassum R, Khaskheli MS, Abbas J, Sultana R, Laghari SH. COVID-19 pandemic and the healthcare workers- The call of duty. J Res Pharm. 2021; 25(6): 937-943. 
This stress endangers not only the physical well-being of the HCWs, but also their psychological well-being [7]. The fear of rapid transmission, public nonseriousness, unpreparedness of healthcare authorities (HCA) and the insufficient number of healthcare facilities (HCF) equipped to deal with COVID-19 are all factors which weigh heavily on the psychological well-being of HCWs. HCWs are not only concerned about their own well-being, but also about the well-being of their families. The resulting anxiety may interfere with the performance of their duties $[1,8]$. During the pandemic, the duty hours of HCWs have been increased and they often have to work with inadequate resources [6]. The increased workload may negatively impact the HCWs who have less time to focus on getting proper nutrition and adequate sleep $[9,10]$. In addition, disinformation on social media about the Coronavirus aggravates this situation by converting this pandemic into an 'infodemic' [11]. This infodemic leads to even more anxiety, fear, and panic in HCWs [12].

COVID-19 has had more negative effects on HCWs in comparison to other epidemics in recent history. Since Pakistan shares a border with China, which was the epicenter of the COVID-19 outbreak, Pakistan has been preparing for the Coronavirus since the outbreak started in late 2019. As of January 10, 2021, the National Command and Operation Center (NCOC) developed by the Government of Pakistan (GOP) to cope up with COVID-19 pandemic, has reported 502,416 confirmed cases of COVID-19 and 10,644 deaths resulting from this virus [4, 13]. Pakistan has long faced serious financial difficulties and lockdowns to combat the Coronavirus will only exacerbate these difficulties. In response to the pandemic, Pakistan must divert scarce financial resources away from other sectors to bolster the health sector [13].

Previously, the majority of the studies conducted have focused on how the pandemic affected patients' stigmatization, level of depression, financial well-being, and, in the case of survivors returning to their communities, the guilt experienced by survivors and their families and their nonacceptance by society [14, 15]. But the impact of the COVID-19 pandemic on the mental health, daily routines, and family and social life of HCWs has remained unclear. This study is designed to gauge the concerns and perceptions of HCWs due to the COVID-19 pandemic and effect of this pandemic on their mental health, routine work, and family and social lives. By understanding these effects, we hope to provide HCAs with information that may assist their efforts to support HCWs in the future during pandemics.

\section{RESULTS}

In total, 412 completely filled forms were received and included in the analysis. The basic demographic characteristics of the participants are shown in Table 1. It was observed that more males particpated than females ( $54.6 \%$ vs $45.4 \%$ respectively). Furthermore, about half of the participants were young in the age group of $18-28$ years $(47.3 \%)$. Moreover, the majority of the participants had a bachelor's degree $(49.5 \%)$ and higher proportion was of doctors $(50.0 \%)$. Depending upon the type of HCF, most of the responses came from government (Govt.) owned tertiary care hospitals (TCHs) (64.1\%), and 35.9\% by private (Pvt.) sector TCHs. It was observed that only $23.3 \%$ of the participants were working in COVID-19 isolation units.

Table 2 and Figure 1 shows the COVID-19 related health concerns and emotional distress. When HCWs were asked how concerned were they that the pandemic has negatively affected their physical and psychological health, the majority of them were very highly worried about their health $(47.7 \%)$, while only $10.9 \%$ were really not concerned about their health. However, compared to concern for their own personal health, more of the HCWs were very highly worried about their family's health (67.7\%). Furthermore, more than half of the HCWs reported that their family life has been very highly affected (51.9\%) due to changes brought by the COVID-19 outbreak. It was found that most of the HCWs thought that precautionary measures taken against COVID-19 in their HCF were of moderate level (47.8\%), and only a few observed very high level $(8.3 \%)$ precautionary measures. When asked about the emotional distress, $38.1 \%$ marked for low emotional distress, while only $14.1 \%$ marked very high emotional distress. Finally, when respondents were asked about the positive outcomes of COVID-19 outbreak, only 9.5\% thought of low positive impact of COVID-19 in future.

There was a significant difference of emotional distress among subgroups of gender $(p=0.041)$ and working in COVID-19 isolation unit $(\mathrm{p}=0.010)$. On the other hand, regarding precautionary measures at HCF, a highly significant correlation was observed among gender $(p=0.015)$, profession $(p=0.000)$ and type of HCF $(p=0.000)$. However, there was no significant difference of education level and precautionary measures at HCF as described in Table 3. 
Table 1. Demography of the participants of the study.

\begin{tabular}{clc}
\hline Variables & Groups & No. (and \%) \\
\hline \multirow{2}{*}{ Gender } & Male & $225(54.6)$ \\
& Female & $187(45.4)$ \\
\cline { 2 - 3 } & 18-28 years & $195(47.3)$ \\
& 29-38 years & $125(30.3)$ \\
& 39-48 years & $49(11.9)$ \\
& 49-58 years & $26(6.3)$ \\
& 59 and Above & $17(4.1)$ \\
\cline { 2 - 3 } Education & Intermediate & $16(3.9)$ \\
& Diploma & $15(3.6)$ \\
& Bachelors & $204(49.5)$ \\
& Masters/Specialization & $168(40.8)$ \\
& Ph.D & $9(2.2)$ \\
\cline { 2 - 3 } & Doctor & $206(50.0)$ \\
& Pharmacist & $122(29.6)$ \\
Profession & Physiotherapist & $12(2.9)$ \\
& Nurse & $37(9.0)$ \\
Type of Health Care & Paramedical staff & $23(5.6)$ \\
Facility & Non-Medical Professional & $12(2.9)$ \\
\cline { 2 - 3 } Isolation Unit & Tertiary Care Hospital (Govt.) & $264(64.1)$ \\
Working in COVID-19 & Tertiary Care Hospital (Pvt.) & $148(35.9)$ \\
\cline { 2 - 3 } & Yes & $96(23.3)$ \\
& No & $316(76.7)$ \\
\hline
\end{tabular}

Table 2. COVID-19 related health concerns and emotional distress.

\begin{tabular}{|c|c|c|c|c|}
\hline Variable & $\begin{array}{c}\text { Low } \\
\text { n ( } \%)\end{array}$ & $\begin{array}{c}\text { Moderate } \\
\text { n (\%) }\end{array}$ & $\begin{array}{l}\text { High } \\
\text { n (\%) }\end{array}$ & $\begin{array}{c}\text { Very high } \\
\text { n (\%) }\end{array}$ \\
\hline Worry about personal health & $45(10.9)$ & $57(13.8)$ & $126(30.6)$ & $184(44.7)$ \\
\hline Worry about family's health & $39(9.5)$ & $25(6.1)$ & $69(16.7)$ & $279(67.7)$ \\
\hline Family life affected & $72(17.5)$ & $51(12.4)$ & $75(18.2)$ & $214(51.9)$ \\
\hline Precautionary measure at $\mathrm{HCF}$ & $90(21.8)$ & $197(47.8)$ & $91(22.1)$ & $34(8.3)$ \\
\hline Emotional Distress & $157(38.1)$ & $123(29.9)$ & $74(18.0)$ & $58(14.1)$ \\
\hline Maintenance of Diet and Rest & $46(11.2)$ & $75(18.2)$ & $53(12.9)$ & $238(57.8)$ \\
\hline $\begin{array}{l}\text { Psychological support from } \\
\text { family }\end{array}$ & $32(7.8)$ & $109(26.5)$ & $101(24.5)$ & $170(41.3)$ \\
\hline Positive impacts in future & $39(9.5)$ & $109(26.5)$ & $93(22.6)$ & $171(41.5)$ \\
\hline
\end{tabular}

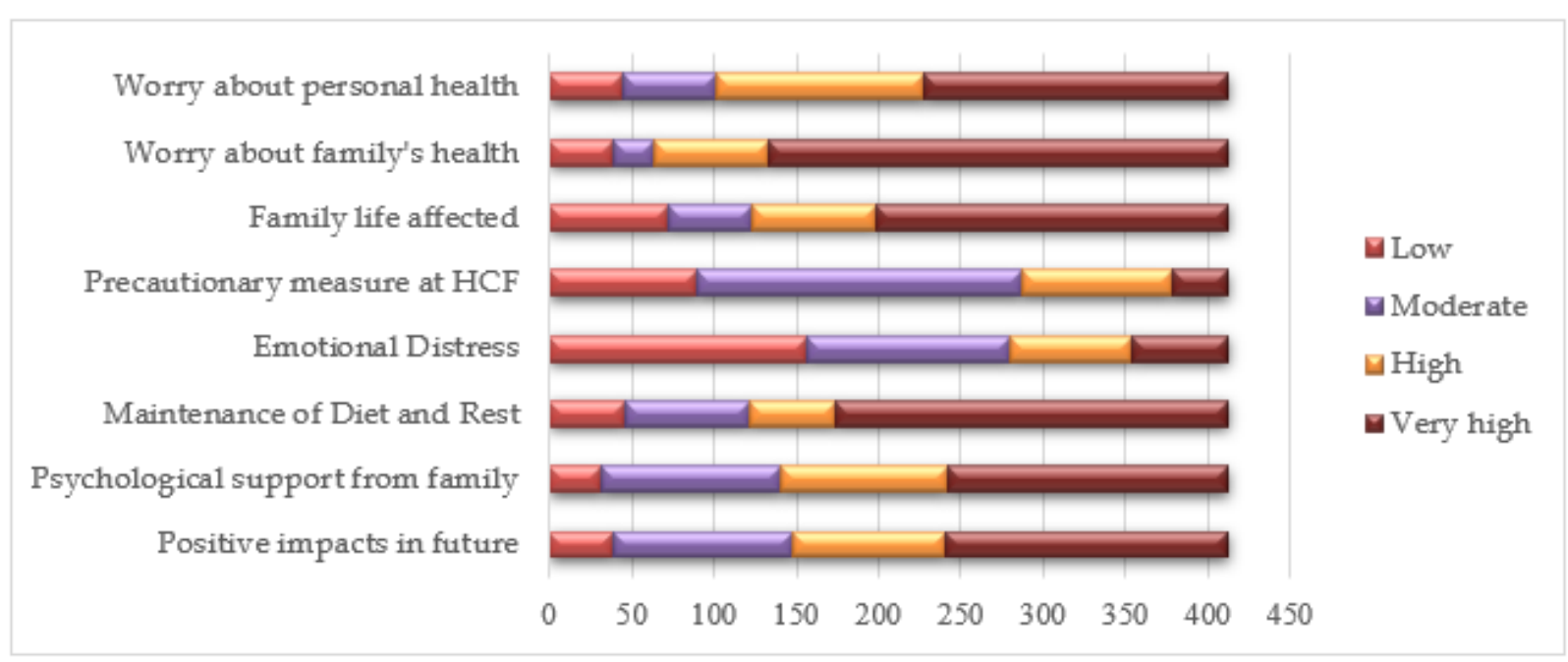

Figure 1. COVID-19 related health concerns and emotional distress. HCF: healthcare facility. 
Table 3. Comparison of emotional distress and precautionary measures at HCF among different categorical variables.

\begin{tabular}{|c|c|c|c|c|}
\hline \multicolumn{5}{|c|}{ Emotional Distress } \\
\hline Variables & Groups & $\mathbf{N}(\%)$ & $\mathrm{X}^{2}$ & P-value \\
\hline \multirow{2}{*}{ Gender } & Male & $225(54.6)$ & 6.375 & 0.041 \\
\hline & Female & $187(45.4)$ & & \\
\hline \multirow{5}{*}{ Education } & Intermediate & $16(3.9)$ & 3.947 & 0.862 \\
\hline & Diploma & $15(3.6)$ & & \\
\hline & Bachelors & $204(49.5)$ & & \\
\hline & Masters & $168(40.8)$ & & \\
\hline & Ph.D & $9(2.2)$ & & \\
\hline \multirow{6}{*}{ Profession } & Doctor & $206(50.0)$ & 12.547 & 0.250 \\
\hline & Pharmacist & $122(29.6)$ & & \\
\hline & Physiotherapist & $12(2.9)$ & & \\
\hline & Nurse & $37(9.0)$ & & \\
\hline & Paramedical staff & $23(5.6)$ & & \\
\hline & NMP & $12(2.9)$ & & \\
\hline \multirow{2}{*}{ Type of Health Care Facility } & Government & $264(64.1)$ & 9.735 & 0.136 \\
\hline & Private & 148 (35.9) & & \\
\hline Working in COVID-19 Isolation & Yes & $96(23.3)$ & 13.178 & 0.010 \\
\hline Unit & No & $316(76.7)$ & & \\
\hline \multicolumn{5}{|c|}{ Precautionary Measures } \\
\hline Variables & Groups & $\mathbf{N}(\%)$ & $\mathrm{X}^{2}$ & P-value \\
\hline \multirow{2}{*}{ Gender } & Male & $225(54.6)$ & 10.531 & 0.015 \\
\hline & Female & $187(45.4)$ & & \\
\hline \multirow{5}{*}{ Education } & Intermediate & $16(3.9)$ & 18.129 & 0.112 \\
\hline & Diploma & $15(3.6)$ & & \\
\hline & Bachelors & $204(49.5)$ & & \\
\hline & Masters & $168(40.8)$ & & \\
\hline & Ph.D & $9(2.2)$ & & \\
\hline \multirow{6}{*}{ Profession } & Doctor & $206(50.0)$ & 58.457 & 0.000 \\
\hline & Pharmacist & $122(29.6)$ & & \\
\hline & Physiotherapist & $12(2.9)$ & & \\
\hline & Nurse & $37(9.0)$ & & \\
\hline & Paramedical staff & $23(5.6)$ & & \\
\hline & NMP & $12(2.9)$ & & \\
\hline \multirow{2}{*}{ Type of Health Care Facility } & Government & $264(64.1)$ & 53.498 & 0.000 \\
\hline & Private & $148(35.9)$ & & \\
\hline Working in COVID-19 Isolation & Yes & $96(23.3)$ & 13.567 & 0.035 \\
\hline Unit & No & $316(76.7)$ & & \\
\hline
\end{tabular}

NMP: non-medical professional

\section{DISCUSSION}

The global pandemic of COVID-19 is not only affecting the mental health of patients, but also the health of HCWs. This study was designed to understand the concerns and perceptions of HCWs due to COVID-19 and its impact on their mental health, work, family and social life.

During the COVID-19 outbreak, with the fear of rapid transmission, more HCWs were concerned about their well-being and the well-being of their families. A similar rate of worry was observed in HCWs in Australia during the A/H1N1 influenza pandemic, where HCWs' concern of getting infected was moderately high. On the contrary, with the 2012 MERS outbreak in Saudi Arabia HCWs were less concerned about getting infected. But a major concern of the family's health was observed in both of the studies $[8,16,17]$ which suggests that pandemic disease put some emotional stress on the HCWs and may make them reluctant to perform their duties properly. Khalid et al reported during 2012 MERS outbreak in Saudi Arabia that 92\% of the HCWs found themselves nervous and scared [8] whereas in this study only one-third of respondents have expressed emotional distress suggesting the HCWs in Pakistan are emotionally stronger. However, those HCWs with assigned duties in isolation units were more anxious. Because HCWs working in isolation units are primarily in direct contact with an infected person and the chances of disease transmission are much higher than in other units. Wu et al and McAlonan et al had reported during 2003 SARS outbreak in China, that 
HCWs assigned duties in isolation wards had two to three times more chances of having post-traumatic stress as compared to those who were not working in epidemic isolation units $[18,19]$. In these circumstances, if HCWs have been given an option to switch the ward, they prefer to change and moved from high-risk to lowrisk units [8]. During the COVID-19 pandemic, HCWs have a lot of stress in providing better health care to infected patients and having a proper diet and rest is very necessary. World Health Organization (WHO) in its guideline has recommended that the HCWs should take proper rest and and diet and in this study it was observed that about two-third of the respondents were properly following the recommended WHO guidelines $[9,10]$ and this will improve physical and mental state of HCWs. Furthermore, not only diet can keep the HCW stronger at the edge of fighting a pandemic but they also need psychological support. It was astonishingly observed in this study that HCWs were having high (24.5\%) to very high (41.3\%) psychological support from their families. The psychological support is quite necessary for HCWs because not everyone treats them well in epidemics. During outbreaks, HCWs being stigmatized and stressed because of working in hospitals are treated differently by society $[1,7,16,20]$ and this may even pressurize them to abandon the job $[17,20]$. Psychological support has proven to be effective and keep the HCWs moving in the crises of the outbreak [8].

Finally, it was also determined if the COVID-19 outbreak can have any positive effect. The greater proportion of the HCWs reported that the COVID-19 outbreak will have positive impacts in future. In the warlike situation, this mindset will surely help to defeat the COVID-19 outbreak. It has been observed in the past that after the epidemics, people go through post-traumatic stress disorders and stigmatization and HCWs were willing to leave or switch the jobs. When this disaster ends, the HCA should conduct psychological sessions for HCWs who have been through stressful conditions or have been working in the most sensitive areas. This will help HCWs to return to their normal family and social lives and contineuing their current jobs. This will also help them in better handling of stressful conditions to come in health sector because we have to be ready for every disaster $[9,19]$.

This is a cross-sectional study conducted online for three months among HCWs of Sindh province of Pakistan during the Public Health Emergency of International Concern. Data is dependent upon the respondent recall ability and honesty as this study was self-reported so that may be subject to recall bias. The study was conducted in Sindh province of Pakistan and the HCWs residing in other provinces of Pakistan may have gone through different stress level. The results may not be representative of other parts of the world as well and should not be generalized. But despite all these limitations, the findings of this study are very valuable during this period of COVID-19.

\section{CONCLUSION}

Our findings indicate that COVID-19 pandemic has a significant psychological impact on frontline soldiers (healthcare workers) particularly they were worried about family's health. Those working in isolation units were more concered about infecting others, this fear along with the availability of limited precautionary measurs was increasing emotional distress among healthcare workers. The HCA should take the measures and provide support to the HCWs so they can deal with the COVID-19 war. Psychological sessions can also be carried out for the HCWs who have been mentally affected. For the moral support of HCWs the government also provide health risk alllowances to the HCWs.

\section{SUBJECTS AND METHODS}

\subsection{Study design}

A web-based cross-sectional study was conducted through an online questionnaire among the HCWs, working in different HCFs throughout the Sindh, Pakistan.

\subsection{Study instrument}

The questionnaire was adapted from the research study conducted by Leslie A. Nickell et al. in 2004 during the SARS outbreak in Canada [1]. The questionnaire was in the English language and included 14 closed-ended questions. The questionnaire was divided into two sections, which included personal characteristics (six questions) and COVID-19- related health concerns and level of emotional distress (eight questions). For COVID-19 related health concerns and level of emotional distress, the 4-point forced Likert scale was used for the responses: 1 point was assigned for low level of concern; 2 points for a moderate level of concern; 3 points for a high level of concern; and 4 points for a very high level of concern for each question. 
There were further questions about the personal health, family's health, affect to the family life, psychological support from family and maintenance of diet and rest. To determine the level of emotional distress, the HCWs were asked questions regarding their general health, their level of stress, amount of sleep, level of selfconfidence, and ability to make decisions. Based on their answers to these questions the level of emotional distress was determined. The level of precaution was determined by identifying different safety measures taken by HCAs such as training sessions for HCWs, the availability of safety equipment and the presence of hand sanitizers and disinfectant sprays at the HCF. The level of positive impact of COVID-19 in the future was determined by asking wether the COVID-19 will give any learning experience, disease control awareness, increased sense of toghethernes or appreciation of life and work. Based on these further subcategories the low, moderate, high and very high levels were determined. Initially, the questionnaire was randomly distributed to $20 \mathrm{HCWs}$. The suggestions and recommendations obtained through the pilot study were incorporated into the questionnaire for clarity. The results of the pilot study were excluded from the final data.

\subsection{Data collection}

The online research study was conducted for a period of three months (October to December 2020). The questionnaire was designed in Google Forms and distributed to the study population through different social media platforms (WhatsApp, Messenger, Facebook) and by e-mail. The study instrument was sent to the HCWs directly and through professional groups. The responses were recorded. A total of $412 \mathrm{HCWs}$ filled the online form during the study period. The participation of respondents was on a volunteer basis and no compensation was paid to the participants. Informed consent was given by all respondents. Before the participant could proceed to the questionnaire, they first were asked to agree to a consent form. The respondents were asked to fill the questionnaire truthfully and to the best of their ability. The confidentiality of the participants was maintained throughout the survey. Ethical approval for the project was obtained from the Ethical Committee of Peoples University of Medical and Helath Sciences for Women, Nawabshah (SBA), through letter No. PUMHSW / SBA / Reg. 371.

\subsection{Data analysis}

The data collected through an online survey was analyzed through SPSS (version. 24, SPSS Inc. Chicago). Descriptive statistics were applied to obtain the frequencies. The Chi-square test was used to determine the relationships between the different categorical variables (gender, education, profession, type of HCF and working in COVID-19 isolation unit) for the level of emotional distress and precautionary measures.

Acknowledgement: We are thankful to all the healthcare workers who during their hectic schedule of duties responded to our questionaire.

Author contributions: Concept - S.M., R.T., G.K.; Design - S.M., N.K., G.K.; Supervision - R.T., M.S.K, J.A.; Resources - R.T., R.S., M.S.K.; Materials - R.S., S.H.L., M.S.K.; Data Collection and/or Processing - R.S., S.H.L., J.A.; Analysis and/or Interpretation - N.K., G.K., J.A.; Literature Search - S.M., R.S., S.H.L.; Writing - S.M., G.K., N.K.; Critical Reviews - S.M., G.K., N.K., R.T., M.S.K., J.A., R.S., S.H.L.

Conflict of interest statement: There is no conflict of interest among the authors.

Ethics committee approval: Ethical approval was taken from Ethical Committee of Peoples Peoples University of Medical and Helath Sciences for Women, Nawabshah (SBA), through letter No. PUMHSW / SBA / Reg. 371.

\section{REFERENCES}

[1] Nickell LA, Crighton EJ, Tracy CS, Al-Enazy H, Bolaji Y, Hanjrah S, Hussain A, Makhlouf S, Upshur RE. Psychosocial effects of SARS on hospital staff: survey of a large tertiary care institution. Can Med Assoc J. 2004; 170(5): $793-798$. [CrossRef]

[2] Perspect OPHR. Middle East Respiratory Syndrome Coronavirus Outbreak in the Republic of Korea, 2015. Osong Public Health Res Perspect. 2015; 6(4): 269-278. [CrossRef]

[3] Peeri NC, Shrestha N, Rahman MS, Zaki R, Tan Z, Bibi S, Baghbanzadeh M, Aghamohammadi N, Zhang W, Haque U. The SARS, MERS and novel coronavirus (COVID-19) epidemics, the newest and biggest global health threats: what lessons have we learned? Int J Epidemiol. 2020: 1-10. [CrossRef]

[4] Ministry of National Health Services Regulation and Coordination Pakistan. CIVID-19 Health Advisory Platform, 2020. http://covid.gov.pk/(accessed on 10 January 2021) 
[5] Ioannidis JPA. Global perspective of COVID-19 epidemiology for a full-cycle pandemic. Eur J Clin Invest. 2020; 50(12): 1-9. [CrossRef]

[6] Muhammad S, Qureshi Y, Tabassum R, Khaskheli MS, Kumar N, Abbas J, Kumari G, Sultana R, Ahmer A, Jamali J. Safety and Awareness of Healthcare Workers During the COVID-19 Outbreak; A Cross-Sectional Study. J Pharm Res Int. 2020; 32(38): 30-38. [CrossRef]

[7] McMahon SA, Ho LS, Brown H, Miller L, Ansumana R, Kennedy CE. Healthcare providers on the frontlines: a qualitative investigation of the social and emotional impact of delivering health services during Sierra Leone's Ebola epidemic. Health Policy Plan. 2016; 31(9): 1232-1239. [CrossRef]

[8] Khalid I, Khalid TJ, Qabajah MR, Barnard AG, Qushmaq IA. Healthcare Workers Emotions, Perceived Stressors and Coping Strategies During a MERS-CoV Outbreak. Clin Med Res. 2016; 14(1): 7-14. [CrossRef]

[9] Maunder RG, Lancee WJ, Balderson KE, Bennett JP, Borgundvaag B, Evans S, Fernandes CM, Goldbloom DS, Gupta M, Hunter JJ, McGillis Hall L, Nagle LM, Pain C, Peczeniuk SS, Raymond G, Read N, Rourke SB, Steinberg RJ, Stewart TE, VanDeVelde-Coke S, Veldhorst GG, Wasylenki DA. Long-term psychological and occupational effects of providing hospital healthcare during SARS outbreak. Emerg Infect Dis. 2006; 12(12): 1924-1932. [CrossRef]

[10] World Health Organization. Mental health and psychosocial considerations during the COVID-19 outbreak, 18 March 2020. https:// www.who.int/docs/default-source/coronaviruse/mental-health-considerations.pdf (accessed on 12 January 2021)

[11] Zarocostas J. How to fight an infodemic. The Lancet. 2020; 395(10225): 676. [CrossRef]

[12] Su T-P, Lien T-C, Yang C-Y, Su YL, Wang J-H, Tsai S-L, Yin J-C. Prevalence of psychiatric morbidity and psychological adaptation of the nurses in a structured SARS caring unit during outbreak: A prospective and periodic assessment study in Taiwan. J Psychiatr Res. 2007; 41(1-2): 119-130. [CrossRef]

[13] Raza S, Rasheed MA, Rashid MK. Transmission Potential and Severity of COVID-19 in Pakistan. Preprints 2020. 2020: 1-10. [CrossRef]

[14] Arwady MA, Garcia EL, Wollor B, Mabande LG, Reaves EJ, Montgomery JM. Reintegration of Ebola survivors into their communities - Firestone District, Liberia, 2014. Morb Mortal Wkly Rep. 2014; 63(50): 1207-1209.

[15] Lee-Kwan SH, DeLuca N, Adams M, Dalling M, Drevlow E, Gassama G, Davies T. Support services for survivors of Ebola virus disease-Sierra Leone, 2014. Morb Mortal Wkly Rep. 2014; 63(50): 1205-1206.

[16] Goulia P, Mantas C, Dimitroula D, Mantis D, Hyphantis T. General hospital staff worries, perceived sufficiency of information and associated psychological distress during the A/H1N1 influenza pandemic. BMC Infect Dis. 2010; 10(1): 1-11. [CrossRef]

[17] Al Ghobain M, Aldrees T, Alenezi A, Alqaryan S, Aldabeeb D, Alotaibi N, Aldhabib A, Alghalibi S, Alharethy S. Perception and attitude of emergency room resident physicians toward middle east respiratory syndrome outbreak. Emerg Med Int. 2017; 2017: 1-4. [CrossRef]

[18] Wu P, Fang Y, Guan Z, Fan B, Kong J, Yao Z, Liu X, Fuller CJ, Susser E, Lu J. The psychological impact of the SARS epidemic on hospital employees in China: exposure, risk perception, and altruistic acceptance of risk. Can J Psychiatry. 2009; 54(5): 302-311. [CrossRef]

[19] McAlonan GM, Lee AM, Cheung V, Cheung C, Tsang KW, Sham PC, Chua SE, Wong JG. Immediate and sustained psychological impact of an emerging infectious disease outbreak on health care workers. Can J Psychiatry. 2007; 52(4): 241-247. [CrossRef]

[20] Shiao JS-C, Koh D, Lo L-H, Lim M-K, Guo YL. Factors Predicting Nurses' Consideration of Leaving their Job During the Sars Outbreak. Nurs Ethics. 2007; 14(1): 5-17. [CrossRef] 